\title{
Pancreatic cancer: What the oncologist can offer for palliation
}

\author{
Malcolm J Moore MD
}

MJ Moore. Pancreatic cancer: What the oncologist can offer for palliation. Can J Gastroenterol 2002;16(2):121-124.

Because pancreatic cancer has a poor survival rate and only 20\% of patients present with potentially resectable disease, a key goal of therapy is to provide palliation. The poor medical condition of many patients interferes with their ability to tolerate traditional chemotherapy. Recently, however, a nucleoside analogue, gemcitabine, has been developed. This drug is more effective than 5-fluorouracil (5-FU), can be used in patients who fail to respond to 5-FU and has only modest toxicity. Combination therapies including gemcitabine and other agents are being tested. Local radiotherapy seems to provide pain relief, but gastrointestinal toxicity is significant. The effect of combined modality therapy (5-FU with radiotherapy) on survival is unclear, and it does not prevent local disease progression. Some novel biological agents, including angiogenesis inhibitors, matrix metalloproteinase inhibitors, antisense compounds, inhibitors of cell signalling such as epidermal growth factor and vascular endothelial growth factor, and inhibitors of oncogene activation, are undergoing phase II and III trials in patients with pancreatic cancer. Among the most promising are farnesyl protein transferase inhibitors, which modulate K-ras function. Such an approach is promising for the treatment of pancreatic cancer because this tumour frequently exhibits mutation of the ras gene.

Key Words: Gemcitabine; Pancreatic cancer

\section{Cancer du pancréas : ce que l'oncologue peut offrir comme traitement palliatif}

RÉSUMÉ : Compte tenu du fait que le taux de survie au cancer du pancréas est faible et que $20 \%$ seulement des patients présentent une maladie potentiellement résécable, l'un des principaux objectifs du traitement consiste à offrir la palliation. Le mauvais état de nombreux patients nuit à leur capacité de tolérer la chimiothérapie classique. Dernièrement, on a cependant mis au point un analogue de nucléoside, la gemcitabine. Le médicament est plus efficace que le 5-fluorouracile (5-FU), il peut être administré à des patients qui ne réagissent pas au 5-FU et il ne présente qu'une faible toxicité. Les polythérapies composées de gemcitabine et d'autres agents font l'objet d'essais. La radiothérapie locale semble procurer un certain soulagement mais est accompagnée d'une forte toxicité gastro-intestinale. On ne connaît pas très bien l'effet de la polythérapie (5-FU et radiothérapie) sur la survie, mais elle n'empêche pas l'évolution locale de la maladie. Certains nouveaux agents biologiques, dont les inhibiteurs de l'angiogenèse, les inhibiteurs des métalloprotéinases de la matrice extracellulaire, les composés antisens, les inhibiteurs de la transmission des signaux cellulaires comme le facteur de croissance épidermique et le facteur de croissance endothéliale ainsi que les inhibiteurs d'activation des oncogènes font l'objet d'évaluation dans des essais de phase II ou III, menés auprès de patients atteints du cancer du pancréas. Parmi les substances les plus prometteuses figurent les inhibiteurs de la farnésyl-transférase, qui modulent la fonction du gène K-ras. Ces inhibiteurs offrent des perspectives encourageantes pour le traitement du cancer du pancréas étant donné qu'on observe souvent une mutation du gène ras dans les tumeurs en cause.

Department of Medicine and Pharmacology, Princess Margaret Hospital, University of Toronto, Toronto, Ontario

Correspondence: Dr Malcolm Moore, Princess Margaret Hospital, Room 5-205, 610 University Avenue, Toronto, Ontario M5G 2M9.

Telephone 416-946-2263, fax 416-946-6546, e-mail malcolm.moore@uhn.on.ca

Received for publication December 3, 2001. Accepted December 3, 2001 
Pancreatic adenocarcinoma is the fourth largest cause of cancer mortality in both men and women in North America, with an estimated 30,000 new cases (and deaths) in 2001. The incidence rate has been stable over the past decade. The overall five-year survival rate is less than $2 \%$, which is the worst survival rate of any cancer (1). While surgery is the only curative option, only $20 \%$ of patients present with localized, and thus potentially resectable, disease. Surgical resection can be associated with considerable morbidity and mortality, and even where possible, the fiveyear survival rate is less than $20 \%$ (2). The goal for the treatment of patients with locally advanced or metastatic disease is not only to improve survival, if possible, but also to provide palliation - that is, to control disease-related symptoms, which can have a devastating effect on the patient. There have been some recent improvements in this regard, which have stimulated a much greater effort to develop even better therapies for this disease (3).

A number of genetic changes are commonly seen in patients with pancreatic cancers. Mutations in the oncogene $\mathrm{K}$-ras are seen in $80 \%$ to $90 \%$ of cases. Deletions of tumour suppressor gene $p 16$ is similarly found in most cases, and $p 53$ and DPC mutations are also common. Overexpression of signal transduction pathways such as epidermal growth factor (EGF) are also common - overexpression of the related protein Her2/neu is seen in fewer than $10 \%$ of cases.

\section{TREATMENT OF PANCREATIC CANCER: SYSTEMIC THERAPY FOR ADVANCED DISEASE}

Notwithstanding the general pessimism about the efficacy of chemotherapy in patients with pancreatic cancer, there has been a major effort to identify agents with some efficacy in the treatment of this disease. The agent evaluated most extensively for the treatment of pancreatic cancer is 5-fluorouracil (5-FU). The optimal schedule and dose have not yet been clearly defined. Biochemical modulation of 5-FU, which has shown some benefit for the treatment of colorectal cancer, has not been helpful for pancreatic cancer (4). The results of combination therapy are unfortunately not better. Randomized trials have shown no survival benefit from the use of combination chemotherapy beyond what is achieved with 5-FU alone. The toxicity of these combination regimens is a problem for many patients (5).

Patients with advanced disease are generally older, suffer from anorexia and malnutrition, and have poor performance status. Concurrent medical problems often include pain, nausea, jaundice and a thrombotic tendency. These factors increase drug toxicity and thus reduce the tolerance to any systemic therapy. In addition, pancreatic cancer is usually a rapidly progressive disease. Unlike some other solid tumours such as breast, colon or prostate cancer, with which patients can have slowly advancing disease and remain clinically stable for many months, the majority of pancreatic cancer patients with metastatic disease have clinical and radiological progression of their disease within one to three months.
In a setting in which chemotherapy has modest activity with little impact on survival, the major goal of therapy is palliation. To assess the palliative effects of chemotherapy, disease-related symptoms, and the trade-off between therapeutic benefit and toxicity need to be assessed. Gemcitabine $\left(2^{\prime}, 2^{\prime}\right.$-difluorodeoxycytidine) is a nucleoside analogue with structural and metabolic similarities to cytarabine. In phase I studies, the weekly regimen offered the best therapeutic ratio. In the initial phase I studies of gemcitabine, tumour shrinkage was seen in patients with pancreatic cancer, leading to two multicentre phase II trials that showed a modest response rate (10\% to $20 \%)$; however, more patients than expected survived one year and more patients' disease had stabilized. There was also evidence of disease palliation (decreased pain and improved performance status) in a larger proportion of patients (6).

To define the palliative gains of therapy, a measure of clinical benefit was developed that incorporated the most important disease-related symptoms. The three primary measures used in this system were pain intensity, analgesic intake and Karnofsky performance status. A beneficial clinical response was defined as a significant and sustained improvement in at least one of these three parameters, with no deterioration in the others. Such a response was the primary end point in two studies of gemcitabine - one a randomized, phase III trial in untreated patients, and the other a phase II trial in patients who had failed to respond to 5-FU.

In the first study, 126 patients with advanced pancreatic adenocarcinoma were randomly assigned to receive either gemcitabine $1000 \mathrm{mg} / \mathrm{m}^{2}$ weekly for seven of eight weeks or 5 -FU $600 \mathrm{mg} / \mathrm{m}^{2}$ weekly (7). A beneficial clinical response was reported in $23.8 \%$ of the gemcitabine-treated patients and $4.8 \%$ of the $5-\mathrm{FU}$ arm $(\mathrm{P}=0.0022)$. Toxicity was modest, in that febrile neutropenia was seen in less than $5 \%$ of patients and there were no bleeding complications. The median survival was 5.7 months in the gemcitabine group compared with 4.47 months in the 5 -FU group $(\mathrm{P}=0.0025)$, and the 12 -month survival rates were $18 \%$ and $2 \%$, respectively.

The second study assessed the clinical benefit of gemcitabine in patients whose disease had progressed despite 5-FU therapy. A beneficial clinical response was achieved in 17 of the 63 patients (27\%) (8). These two studies of gemcitabine in advanced pancreatic carcinoma have demonstrated a benefit in terms of both disease palliation and survival. This is important given the generally poor condition of these patients and the limited therapeutic options available. It was for this reason that regulatory authorities in the United States and Canada approved gemcitabine for the treatment of advanced pancreatic cancer (9).

Since gemcitabine has been approved for the palliative treatment of pancreatic cancer, there have been attempts to build on this initial success. The most common approaches have been the use of gemcitabine-based combination chemotherapy, the combination of biological agents with gemcitabine and the use of gemcitabine in earlier stages of 
the disease. Many of these treatment approaches are presently undergoing phase III trials in Canada and the United States. The most common chemotherapy combinations being tested are gemcitabine plus 5-FU, cisplatin, docetaxel or irinotecan. Studies so far have demonstrated no benefit from combining gemcitabine with 5-FU. Studies comparing the other three combinations with single-agent gemcitabine have recently been completed in Europe and the United States, and are due to be reported later in 2002.

In Canada, the approach has been to examine combinations of gemcitabine with novel biological agents. The initial study done through the National Cancer Institute of Canada examined the matrix metalloproteinase and antiangiogenic agent BAY 12-9566. While there was preclinical evidence of antitumour activity with BAY 12-9566, there was no evidence of benefit in patients. The current National Cancer Institute of Canada study is comparing single-agent gemcitabine with the combination of gemcitabine and the EGF inhibitor OSI-774.

\section{USE OF CHEMOTHERAPY TO PREVENT RECURRENCE}

Given that all patients who undergo a Whipple's procedure are at high risk of developing recurrent disease, it is surprising that there have been so few randomized trials of adjuvant therapy. The high local failure rate has led to the inclusion of radiation therapy as adjuvant therapy in most protocols. An old study of the Gastrointestinal Tumor Study Group (GITSG) provided evidence in favour of using both chemotherapy and radiotherapy following surgery. Although this study showed that combined modality therapy offered a modest therapeutic advantage, only 40 patients were included over a seven-year period (10). More recent studies done in Europe comparing adjuvant 5-FU therapy plus radiation with either 5 -FU alone or no adjuvant therapy have included several hundred patients, but the results are not yet available. These trials should provide more definite evidence of the role of adjuvant therapy. Gemcitabine is known to be a potent radiosensitizer, and dose-ranging studies of combinations of gemcitabine, 5-FU and radiotherapy, in the adjuvant setting, are currently underway (11).

\section{LOCALLY ADVANCED DISEASE: THE ROLE OF RADIATION AND CHEMOTHERAPY}

Approximately $30 \%$ of patients with pancreatic cancer present with locally unresectable disease with no demonstrated distant metastases. Thus, local disease control is important and can provide useful palliation. The current standard in North America is to use a combination of chemotherapy and radiation therapy for many of these patients. This strategy is based on an old study of the GITSG, in which 194 patients with locally advanced disease were randomly assigned to receive high-dose radiation (6000 cGy), high-dose radiation with concurrent 5-FU, or lower dose radiation (400 cGy) with concurrent 5-FU. Median survival (40 versus 20 weeks) improved with both combined modality treatments compared with radiation therapy alone (12). The lower dose of radiation was recommended due to excessive toxicity from the use of higher doses with 5-FU. A subsequent follow-up study by GITSG compared combined modality therapy with chemotherapy alone in the same population. This relatively small study showed a modest improvement in median survival with the use of combined modality therapy. On the other hand, a study by The Eastern Cooperative Oncology Group did not demonstrate any survival benefit from treatment with 5-FU plus radiation compared with radiation alone $(13,14)$.

Radiation therapy applied to the pancreas also has palliative benefits, in that approximately $50 \%$ of patients report significant improvements in pain (15). The high local progression rate with combined modality therapy has led to studies of more intensified local external beam radiation in combination with either implants or intraoperative radiation. Some studies have shown improvement in local control from such approaches, but there has been no impact on survival. In addition, the gastrointestinal toxicity of higher dose radiation regimens is a significant problem. Given that many patients with locally advanced disease develop distant metastatic disease within six months of presentation, the outcome of these patients will not improve much further until effective systemic therapy is available (16).

\section{FUTURE PROSPECTS}

Since gemcitabine has been licensed for the treatment of pancreatic cancer, there has been a major increase in clinical research activity. The most interesting new approaches to the systemic therapy of pancreatic cancer do not use 'conventional' cytotoxic agents. In the past 10 years, there has been a vast increase in knowledge of the biology of cancer. From this knowledge has come agents that are targeted against specific characteristics of the cancer cell, such as oncogene expression or tissue invasion. Many of these agents are presently in phase II and phase III trials. These novel approaches include angiogenesis inhibitors, matrix metalloproteinase inhibitors, antisense compounds, inhibitors of cell signalling such as EGF and vascular endothelial growth factor, and inhibitors of oncogene activation $(17,18)$.

Of all of these new approaches, possibly the most promising is the use of farnesyl protein transferase inhibitors as modulators of ras function. In order for the ras protein to function, it needs to bind to the cell membrane through an enzymatically controlled reaction (farnesylation). Several farnesyl protein transferase inhibitors have completed phase I testing, and phase II and III trials are either ongoing or about to open. These agents are generally administered orally and are given continuously; some have minimal toxicity. Pancreatic cancer will be one of the first diseases in which these agents will be studied because of the high incidence of ras mutation. 
The past five years have seen the introduction of the first cytotoxic agent approved for the treatment of pancreatic cancer, and an upsurge of interest in studying both the basic biology and the treatment of this disease. Many novel approaches based on good basic science are being tested in clinical trials. For the first time, there is genuine cause for optimism that further inroads against this disease will soon be made.

\section{REFERENCES}

1. Warshaw A, Fernandez C. Pancreatic carcinoma. N Engl J Med 1992;326:455-60.

2. Edge SB, Schmieg RE Jr, Rosenlof LK, Wilhelm MC. Pancreas cancer resection outcome in American university centers. Cancer 1993;71:3502-8.

3. Evans DB, Lee JE, Pisters PW, et al. Advances in the diagnosis and treatment of adenocarcinoma of the pancreas. Cancer Treat Res 1997;90:109-25.

4. Moore MJ, Erlichman C, Kaizer L, Fine S. A phase II study of 5-fluorouracil, leucovorin, and interferon-alpha in advanced pancreatic cancer. Anticancer Drugs 1993;4:555-7.

5. Phase II studies of drug combinations in advanced pancreatic carcinoma. Gastrointestinal Tumor Study Group. J Clin Oncol 1986;4:1794-9.

6. Michael M, Moore M. Clinical experience with gemcitabine in pancreatic carcinoma. Oncology 1997;11:1615-22.

7. Burris H, Moore MJ, Andersen J, et al. Improvements in survival and clinical benefit with gemcitabine as first-line therapy for patients with advanced pancreas cancer: a randomized trial. J Clin Oncol $1997 ; 15: 2403-13$.
8. Rothenberg M, Moore MJ, Cripps C, et al. A phase II trial of gemcitabine in patients with 5-FU refractory pancreas cancer. Ann Oncol 1996;7:347-53.

9. Moore MJ. Activity of gemcitabine in patients with advanced pancreatic carcinoma. A review. Cancer 1996;78:633-8.

10. Regine WF, John WJ, Mohiuddin M. Adjuvant therapy for pancreatic cancer: current status. Front Biosci 1998;3:E186-92.

11. Robertson JM, Shewach DS, Lawrence TS. Preclinical studies of chemotherapy and radiation therapy for pancreatic cancer. Cancer 1996;78:674-9.

12. Treatment of locally unresectable carcinoma of the pancreas. Comparison of combined modality therapy to chemotherapy alone. Gastrointestinal Tumor Study Group. J Natl Cancer Inst 1988;80:751-5.

13. Moertel CG, Frytak S, Hahn RG, et al. Therapy of locally unresectable pancreatic carcinoma: a randomized comparison of high dose (6000 rads) radiation alone, moderate dose radiation (4000 rads + 5-fluorouracil), and high dose radiation + 5-fluorouracil: The Gastrointestinal Tumor Study Group. Cancer 1981;48:1705-10.

14. Poen JC, Ford JM, Niederhuber JE. Chemoradiotherapy in the management of localized tumors of the pancreas. Ann Surg Oncol 1999;6:117-22.

15. Hsue V, Wong CS, Moore M, Erlichman C, Cummings BJ, MacLeod M. A phase I study of combined radiation therapy with 5 -fluorouracil and low dose folinic acid in patients with locally advanced pancreatic or biliary carcinoma. Int J Radiat Oncol Biol Phys 1996;34:445-50.

16. Molinari M, Helton W, Espat NJ. Palliative strategies for locally advanced unresectable and metastatic pancreatic cancer. Surg Clin N Am 2001;81:651-66.

17. Jones L, Ghaneh P, Humphreys M, Neoptolemos JP. The matrix metalloproteinases and their inhibitors in the treatment of pancreatic cancer. Ann N Y Acad Sci 1999;880:288-307.

18. Bramhall SR, Rosemurgy A, Brown PD, Bowry C, Buckels JAC. Marimastat as first-line therapy for patients with unresectable pancreatic cancer: a randomized trial. J Clin Oncol 2001;19:3447-55. 


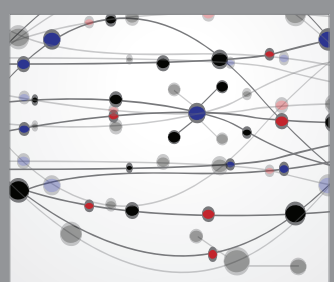

The Scientific World Journal
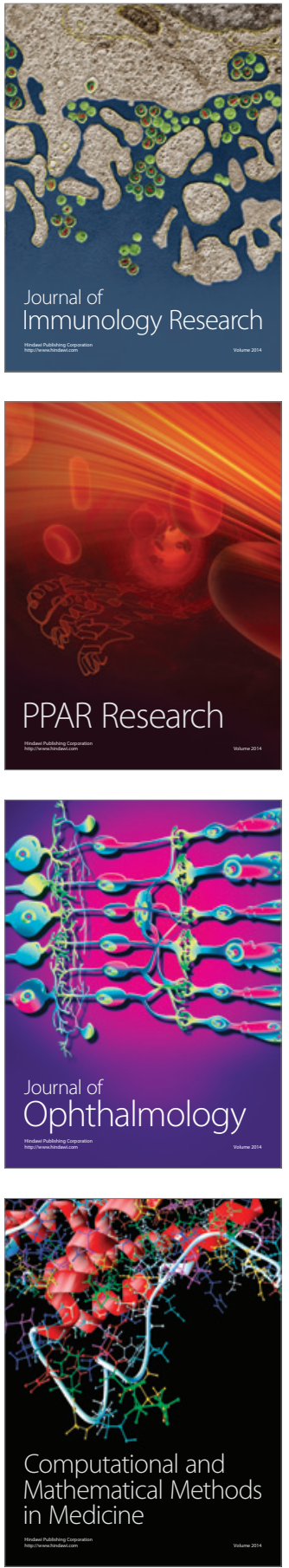

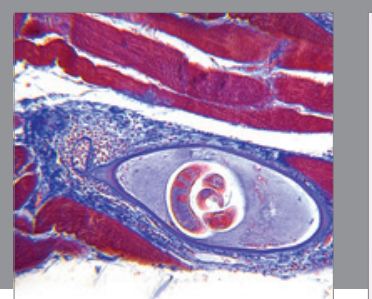

Gastroenterology Research and Practice

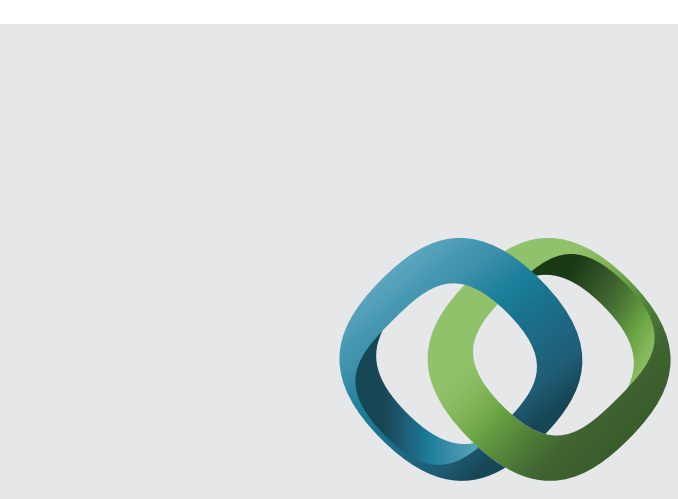

\section{Hindawi}

Submit your manuscripts at

http://www.hindawi.com
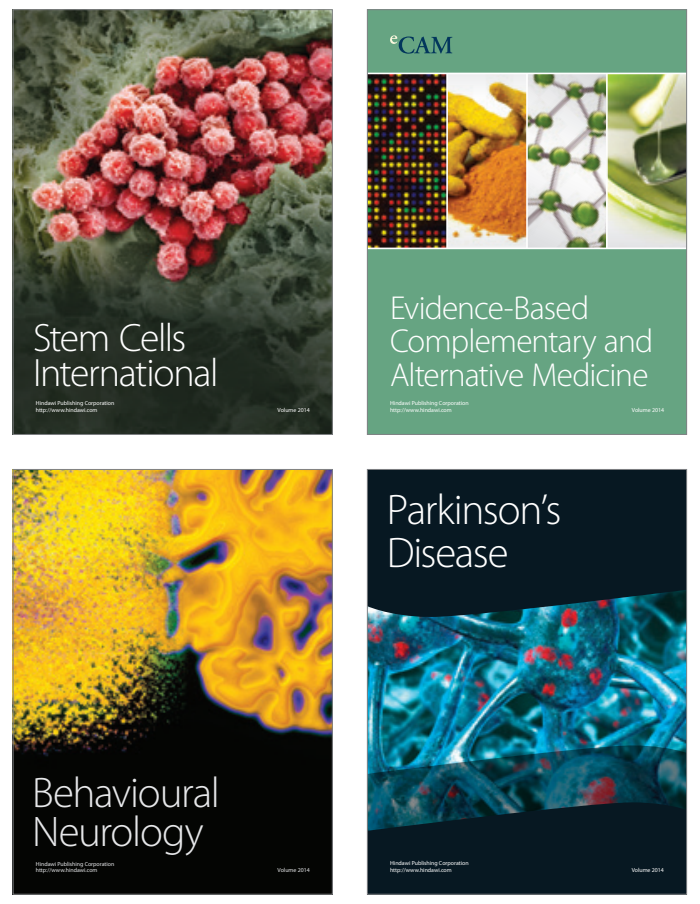
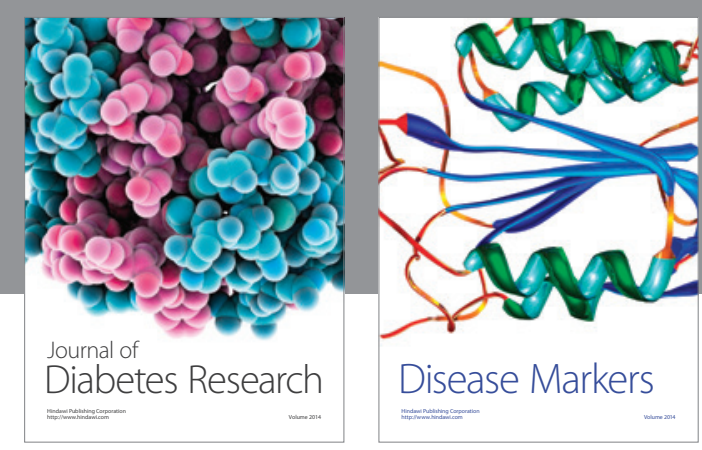

Disease Markers
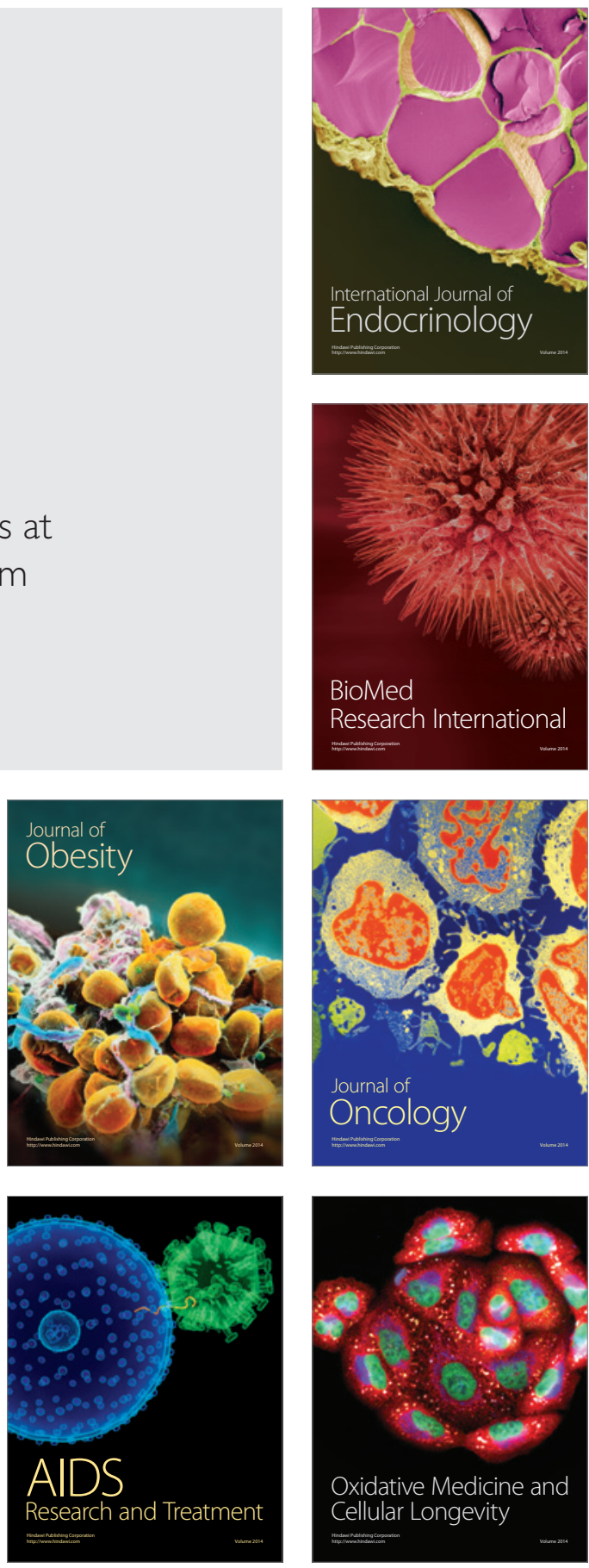